\title{
Neue Microlepidopteren von Sarepta
}

\author{
beschrieben von
}

B. Möschler in Kron-Förstchen bei Bautzen.

Pempelia Deformella nov. sp. Alis anticis griseis, subtiliter albido pulverulentis, punctis duobus discoidalibus nigris, alis posticis cinereis, cupreo-micantibus. $23-25 \mathrm{Mm} . \delta^{7}$ ㅇ.

Fühler graugelb, der Schuppenwulst an der Wurzel dunkelbraungrau, weifslich gemischt. Palpen aufsen heller und dunkler grau, innen, sowie die Nebenpalpen gelblich. Kopf gelbgrau, Thorax aschgrau, Hinterleib unten heller, gelbgrau. Beine aufsen aschgrau, innen gelblich, Tarsen fein gelblich geringelt.

Vorderflügel aschgrau, sparsam fein weifs bestäubt, ohne Spuren von Querbinden, auf dem Querast zwei übereinander stehende schwarze Punkte, welche selten deutlich sind.

Saumlinie bräulich, Franzen gelbgrau mit drei dunkeln Theilungslinien.

Hinterflügel gelbgrau, kupferglänzend, Saumlinie fein braun, Franzen weifsgelb mit drei dunkeln Theilungslinien, deren erste dem Saum näher als den beiden andern und stärker ist. Unterseite der Vorderflügel glänzend braungrau, Hinterflügel wie oben. $2 \Im, 2$ ㅇ.

Nephopteryx Nucleolella nov. sp. Alis anticis dilute cinereis, nigro albidoque pulverulentis, basi fasciisque duabus transversis fulvis, punctisque duabus discoidalibus nigris. Alis posticis albis, ex parte nitido cinereis, vena 5 deficiente. 14-19 Mm. $ठ 7$ ㅇ․

Fühler gelbgrau, Palpen hellgrau, aufsen an Wurzel, Mitte und Spitze dunkelgrau gefleckt. Beine schwarzgrau, weifs bestäubt, die Tarsen weifs geringelt. Kopf und Thorax aschgrau, Hinterleib gelblichgrau.

Vorderflügel schmal mit schwach 留gebogenem Saum, licht aschgrau, fein weifs und schwärzlich bestäubt, besonders auf den Rip- 
pen und am Vorderrand. Wurzelfeld matt röthlichgelb bestäubt, der vordere Querstreif vom Vorderrande saumwärts gebogen, von der innern Mittelrippe weniger schräg zum Innenrand ziehend, rothgelb, in ihm, gegen die Wurzel, einige schwach aufgeworfene dunkelbraune Schuppen, saumwärts begrenzt ihn, wenigstens die obere Hälfte, feine schwärzliche Bestäubung. Der hintere Querstreif nahe dem Saum und mit ihm parallel laufend, in Zelle $1 b$ in einem feinen Strahl in das Mittelfeld tretend, den Vorderrand erreicht dieser Querstreif nicht ganz; den $\mathrm{Z}_{\text {wischenraum füllt tiefschwarze Be- }}$ stäubung aus, welche als Schatten in das Mittelfeld zieht. Nach innen ist dieser Streif fein weifs gesäumt. Auf dem Querast steben zwei schwarze Punkte übereinander. Das schmale Saumfeld ist grau, längs dem Querstreif schwärzlich bestäubt. Saumlinie schwärzlich, Franzen grau, mit zwei schwärzlichen Theilungslinien. Hinterflügel weifs, am Vorderrand und gegen die Spitze gelbgrau glänzend. Saumlinie bräunlich, Franzen schneeweifs, mit verloschener bräunlicher Theilungslinie.

Vorderflügel unten graulich, Vorderrand schmal weifsgelb, beide Querstreifen scheinen verloschen licht durch.

Hinterflügel wie oben. Ast 5 fehlt. $1 \delta^{\nearrow, 2} 2$ ㅇ․

Die Ausbiegung sowie der Schuppenwulst der Fühlerwurzel und die kleinen einfachen Nebenpalpen des Mannes stellen diese Art zu Nephopteryx, das Fehlen von Ast 5 der Hinterflügel weist $\boldsymbol{N u}$ cleolella ihre Stelle bei Dahliella H. an.

Grapholitha Tetraplana nov. sp. Alis anticis aureo-brunneis, basi, disco et speculi limbo albidis, lineis discoidalibus quatuor plumbeis ex quatuor strigulis costalibus; speculo pallido, nigro-quadrimaculato, punctisque tribus argenteis. $\delta$ 우.

Fühler schwärzlich, weifs bestäubt, Palpen weifs, am Endgliede grau. Kopf, Thorax und Hinterleib weifsgrau, Beine weifs, Tarsen dunkel geringelt. Vorderflügel goldbraun, doch ist die Grundfarbe nur in zwei Querbinden vor und hinter der Mitte und gegen die Flügelspitze hervortretend.

Wurzel, eine Mittelbinde und die Umgränzung des Spiegels weifslich. Von den vier starken weifsen Vorderrandshäkchen ziehen ebenso viel Bleilinien zum Spiegel. Dieser ist langgezogen, viereckig, hellgelb, und wird an beiden Seiten und in der Mitte durch je drei Silbertropfen in zwei Felder getheilt, und in jedem derselben stehen vier ins Quadrat gestellte schwarze Fleckchen. Franzen weifs, mit zwei feinen schwarzen Theilungslinien. Hinter- 
flügel licht braungrau, Franzen weifs mit zwei bräunlichen Theilungslinien. Unterseite der Vorderflügel graubraun, Innenrand weifslich, Saumlinie fein weifs, Vorderrandshäkchen weifs. Hinterflügel weifs oder graubraun. 3 ऽt, 2 ㅇ.

Am nächsten bei Pupillana L. - Absinthiana Hb. - stehend.

Butalis Pudorinella nov. sp. Abdomine aeneo-viridi, $\sigma$ gracili, fasciculo anali olivaceo-piloso, $q$ immaculato. Alis anticis elongatis, viridi-aeneis, nitidis, posticis angustioribus, nigro-cinereis, ciliis brunneis vel nigricantibus, nitidis. $15-18 \mathrm{Mm} . \sigma^{\top}$.

Fühler, Palpen, Kopf, Thorax, Hinterleib und Beine erzgrün beschuppt. Der Hinterleib des Mannes schlank, an der Spitze mit zusammengedrücktem, schwach zugespitztem Afterbüschel, der des Weibes ebenfalls ziemlich schlank, doch stärker als der des Mannes, auf der Bauchseite ohne weifse Zeichnung. Die Vorderflügel schmal und spitz, erzgrün mit gleichmäfsiger, ziemlich starker, gelblicher Bestäubung, die Franzen glänzend bräunlichgrau. Hinterflügel sehr schmal und spitz, braungrau, Saumlinien fein gelblich, Franzen wenig heller, als auf den Vorderflügeln. Pudorinella steht am nächsten bei Seliniella Zell. und Amphonycella Hb. (Dorycmiella Mill. kenne ich nicht.) Von beiden unterscheidet sie sich durch spitzere, schmälere Flügel von Seliniella, mit welcher sie in der Färbung übereinstimmt, überdies durch die dicht anliegende Behaarung des Endgliedes des Hinterleibes beim Mann und der fehlenden weifsen Färbung der beiden letzten Bauchsegmente beim Weib. Amphonycella ist leicht durch die viel dunklere, mehr blaugrüne Färbung zu unterscheiden. $3 \sigma, 1$ \& Anfang Juni gefangen.

Coleophora Botaurella nov. spec. Antennis stramineis, cum penicillo basali longiore, et dimidio basali in dorso piloso cristato. Palpis, thorace, abdomine et pedibus stramineis. Alis anticis stramineis, venis plus minusve pallide brunneis. Alis posticis griseis, ciliis brunneo-stramineis.

22-24 Mm. $\delta$ 오.

Fühler hell strohgelb, mit starkem Pinsel an der Wurzel und bis über die Hälfte durch starke haarähnliche Schuppen verdickt. Palpen, Kopf, Thorax und Beine hell strobgelb, Thorax bräunlich, dicht strohgelb bestäubt. Vorderflügel etwas höher strohgelb, die aus der vorderen Mittelrippe in den Vorderrand auslaufenden Rippen bleich bräunlich, bei einem Exemplar fast gelb und wenig über die Grundfarbe vortretend, der Vorderrand sehr fein weifsgelb; 
B. Möschler: neue Microlepidopteren.

Hinterflügel grau, glänzend. Franzen aller Flügel gelblich, mit einem Stich ins Bräunliche. Unten die Vorderflügel braungrau, der Vorderrand und bei einigen Exemplaren auch die Spitze gelblich. $3 \sigma$ und 1 우 Ende August gefangen.

Diese Art ist mit keiner der bekannten zu verwechseln, von Wockeella Zell. und Phlomidella Chrstph., mit welchen sie im Habitus die meiste Aehnlichkeit besitzt und zwischen denen sie in der Gröfse mitten inne steht, unterscheidet sie aufser der ganz verschiedenen Färbung auch der starke Haarpinsel der Fühlerwurzel. 


\section{$2 \mathrm{BHL}$ Biodiversity Heritage Library}

Möschler, B . 1866. "Neue Microlepidopteren von Sarepta." Berliner entomologische Zeitschrift / herausgegeben von dem Entomologischen Vereine in Berlin 10(103),147-150. https://doi.org/10.1002/mmnd.18660100111.

View This Item Online: https://www.biodiversitylibrary.org/item/34396

DOI: https://doi.org/10.1002/mmnd.18660100111

Permalink: https://www.biodiversitylibrary.org/partpdf/210057

\section{Holding Institution}

Smithsonian Libraries

\section{Sponsored by}

Smithsonian

\section{Copyright \& Reuse}

Copyright Status: Public domain. The BHL considers that this work is no longer under copyright protection.

This document was created from content at the Biodiversity Heritage Library, the world's largest open access digital library for biodiversity literature and archives. Visit BHL at https://www.biodiversitylibrary.org. 